\title{
Dynamics of the interaction between body fluid and Ti cp: the influence of surface functionalization in the first stages of osseointegration
}

\author{
Rodney Marcelo do Nascimento*, Vanessa Rafaela de Carvalho
}

\begin{abstract}
Introduction: Regenerative therapies using biomaterials require accurate information on interactions between the implanted material and the human body. To improve the process of bone regeneration it is necessary to obtain a better understanding of the influence of the surfaces on the early stages of osseointegration. This work aims to investigate the dynamic interaction between simulated body fluid (SBF) and titanium surfaces (Ti $\mathrm{cp}$ ) immediately after their first contact. Methods: Ti cp samples were passed through physicochemical treatments after immersion in acid solution, alkaline solution and solutions containing $\mathrm{TiO}_{2}$ and $\mathrm{Ca}^{2+}$, to obtain three different surfaces. These were characterized by electron microscopy and free energy estimates. The evaluation of the interaction with SBF was performed by measuring the dynamic contact angles after contacting the surfaces. Results: The effects of SBF wettability were more significant on surfaces according to high energy estimates. A comparative analysis of the three types of surfaces showed that fluid spreading was greater in samples with greater polar components, indicating that the surface nature influences interactions in the early stages of osseointegration. Conclusion: The results indicate the influence of polar interactions in the dynamic wettability of the SBF. It is possible that these interactions can also influence cellular viability on surfaces. Based on these results, new experiments are being designed to improve the presented methodology as a tool for the evaluation of biomaterials without the need for in vivo experiments.
\end{abstract}

Keywords Osseointegration, Body fluid, Wettability, Surface free energy.

\section{Introduction}

The loss of a body part is a constant concern since ancient times. There has been a continuous search for biomaterials for treatment, enhancement or replacement of tissues, organs and body functions. This search has led to the development of several bioactive surfaces that can promote a better connection with bone (i.e., osseointegration) through a physical-chemical bond between the implant and bone. (Galdino and Zavaglia, 2012; Giavaresi et al., 2003; Kizuki et al., 2010; Nascimento, 2011; Stevens, 2008). Despite the significant advances in the science and technology of biomaterials, information about the chemical nature and spatial dimensions (e.g., roughness and topography) of the materials is needed to have a better understanding of their impact in the first stages of tissue regeneration.

Bone-integration may be interpreted as a dynamic system governed by interactions that occur between ordered, structural and functional bone around the surface of an implant, in the absence of a fibrous layer. This is a result of the physical-chemical bonds at the interfaces between the material and the biological environment. Past research has identified the importance of early stage phenomena in tissue regeneration (Branemark et al., 1987; Giavaresi et al., 2003).
In this process, there is an initial contact between body fluids and the surface of the implant. The fluid volume surrounding the implant material varies and is dependent on the geometry of the implant and the surgical implantation technique (Bruce et al., 2003). In the following stages, the implant compresses the bone and comes in contact with blood and a variety of cells (Boyan et al., 1996). At later stages, the implant surface contacts the marrow bone, cortical bone and trabecular bone (Giavaresi et al., 2003). For proper integration, all stages must allow bone tissue formation around the implant material. Because of the variety of bone tissue at the implant location, mineralization and re-mineralization processes occur at multiple interfaces. Both the nature of the surface and the external environment in which the surface is in contact, are important in the process.

For different phases of interaction, there are interfaces in which systems interchange from one phase to another. In these systems, the interfacial free energy, or the work that must be done to extend or decrease their interfacial limit, is dependent on short and long-range forces (Israelachvili, 1992). For implant materials, such as titanium, interfaces 
are formed in the multilayer structures of oxides and the surrounding biological environment. The functional groups resulting from distinct interfacial interactions are caused by chemical heterogeneity from the environment and are dependent on the types of surfaces present. Calcium phosphate coatings have been shown to be effective in inducing apatite formation, forming an interface that promotes cell proliferation and bone growth (Abdel-Fattah et al., 2008; Thein Han et al., 2012).

After biomaterial application, the first stages of regeneration begin to occur and are directly influenced by the surface energy which affects the following stages. These processes are difficult to simulate. For this reason, it is necessary to use the most simplified physical-chemical models. In this way, this study was aimed at obtaining a better understanding of the phenomena related to bone regeneration in the early stages of the osseointegration process, using as a model system titanium surfaces with physicochemical changes and simulated body fluid. The microstructure and morphology of the surfaces were characterized by scanning electron microscopy, and the surface profile was determined by atomic force microscopy. The surface free energy was estimated from measurements of static contact angles using liquids with different physical and chemical properties. The dynamic interaction between body fluids and surfaces was studied by evaluating the wettability, as measured by the dynamic contact angle. Subsequently, data were compared with cell viability tests.

\section{Methods}

\section{Materials}

Samples $\left(1.0 \times 1.0 \mathrm{~cm}^{2}\right)$ of commercially pure titanium (Ti cp) grade 2 ASTMF67 (Bionnovation implantes e biomateriais, Bauru, São Paulo, Brasil), were used as a model system. The samples were divided into three groups (A, B and C) in which the surfaces were treated by polishing processes, followed by washes in an ultrasonic bath and drying at $60{ }^{\circ} \mathrm{C}$. For the functionalization of the surfaces, group A samples underwent an acid treatment by immersion in 10\% $\mathrm{HCl}$ solution for 30 minutes and were then washed with deionized water and dried at $100^{\circ} \mathrm{C}$ for 1 hour. Group B samples underwent an alkali treatment by immersion in a $1 \mathrm{~mol} / \mathrm{L} \mathrm{NaOH}$ solution for 30 minutes and were then washed in deionized water and dried at $100{ }^{\circ} \mathrm{C}$ for 1 hour, followed by heat treatment at $400{ }^{\circ} \mathrm{C}$ for 1 hour. Group $\mathrm{C}$ samples were immersed in a calcium solution. The calcium solution was obtained by mixing two solutions in a 1:1 ratio. The first solution consisted of acetic acid, isopropyl alcohol, nitric acid, distilled water and isopropoxy titanium. The second solution consisted of hydrated calcium nitrate and isopropyl alcohol. Finally, group $\mathrm{C}$ samples were heat treated at $700{ }^{\circ} \mathrm{C}$ for 1 hour. This surface functionalization was adapted from an ion condensation/sol gel technique (Nascimento, 2011).

\section{Surfaces characterization}

The surface functionalization was evaluated by estimating the free energy from dispersive $\left(\gamma^{d}\right)$ and polar $\left(\gamma^{p}\right)$ interactions (Kaelble and Uy, 1970; Owens and Wendt, 1969).

$$
\gamma_{L V}(1+\cos \theta)=2\left(\gamma_{S}^{d} \gamma_{L V}^{d}\right)^{1 / 2}+2\left(\gamma_{S}^{p} \gamma_{L V}^{p}\right)^{1 / 2}
$$

The contact angle $\theta$ was determined by a tensiometer/goniometer (OCA 20, Dataphysics, Germany), using water $\left(\gamma_{\mathrm{LV}}^{\mathrm{p}}=51 \mathrm{~mJ} / \mathrm{m}^{2}\right.$ and $\gamma^{\mathrm{d}}{ }_{\mathrm{LV}}=21.8 \mathrm{~mJ} / \mathrm{m}^{2}$ ) and dimethyl sulfoxide $\left(\gamma^{\mathrm{p}}=8.68 \mathrm{~mJ} / \mathrm{m}^{2}\right.$ and $\left.\gamma_{\mathrm{LV}}^{\mathrm{d}}=34.83 \mathrm{~mJ} / \mathrm{m}^{2}\right)$. After determining the droplet profile, the contact angle was measured to determinate the adhesion work and surface energy of the samples ( $\gamma_{\mathrm{s}}^{\mathrm{d}}$ and $\gamma_{\mathrm{s}}^{\mathrm{p}}$, respectively).

Morphological analyses of the surfaces, in terms of roughness and microstructures, were performed by scanning electron microscopy (SEM) with a 515-Philips, and atomic force microscopy (AFM) by means of Shimadzu SPM version 2.0.

\section{Dynamics of interaction}

The dynamic interactions at the interfaces between the Ti cp with modified surfaces and the biological environment were studied by macroscopically observing the behavior of a simulated body fluid (SBF) drop on each surface, and correspondingly evaluating the wettability of each sample group. The simulated body fluid was obtained through a protocol described by Kokubo (1991) by mixing $0.2 \mathrm{~g} \mathrm{KCl}$, $8.0 \mathrm{~g} \mathrm{NaCl}, 0.2 \mathrm{~g} \mathrm{CaCl}_{2} 2 \mathrm{H}_{2} \mathrm{O}, 0.05 \mathrm{~g} \mathrm{NaH}_{2} \mathrm{PO}_{4}, 1.0 \mathrm{~g}$ $\mathrm{NaHCO}_{3}, 0.1 \mathrm{~g} \mathrm{MgCl}_{2} .6 \mathrm{H}_{2} \mathrm{O}$ and $1.0 \mathrm{~g}$ glucose in $1,000 \mathrm{ml}$ of water at a constant $\mathrm{pH}$ of 7 (to prevent precipitation). To identify the macroscopic effect of the interactions at the interface (thereby studying the dynamics of interaction), the contact angles of the fluid were measured by camera and software that captured images at 0.05 and 0.1 second intervals. The drop volume was kept constant at $10 \mathrm{ml}$. The temperature of the chamber was maintained at $25 \pm 1{ }^{\circ} \mathrm{C}$. First, different intervals time were evaluated to determine the behavior of the droplet on the surface SBF. The variation of the water contact angle versus time was calculated and converted to radians per second using Dataphysics OCA 20. These experiments were conducted at the Faculdade de Filosofia e Letras, USP, Ribeirão Preto. Data regarding the contact angle 
change as a function of time were analyzed using Origin 8.5 software and the spreading speed of the liquid was measured in radians/second.

\section{Cell viability}

To study the cytotoxicity of the surfaces, L929 cells cultured in RPMI 1640 supplemented with 10\% fetal bovine serum, $2 \mathrm{mM}$ L-glutamine, $20 \mathrm{mM}$ HEPES and $0.2 \%$ sodium bicarbonate, were used. This solution is referred to as complete RPMI. Cells were re-suspended in RPMI at a concentration of $2 \times 10^{4}$ cells $/ \mathrm{mL}$. Cell growth was measured at different periods of the culture: $24 \mathrm{~h}, 48 \mathrm{~h}, 72 \mathrm{~h}, 96 \mathrm{~h}, 120 \mathrm{~h}$ and $144 \mathrm{~h}$. Cell samples on a culture plate were treated with $0.2 \%$ vital stain crystal violet in $20 \%$ ethanol and incubated for $10 \mathrm{~min}$ at room temperature. The dye was discarded and the plate was gently washed with distilled water to remove the residual dye. After drying the plate at $37^{\circ} \mathrm{C}$, the stained cells were solubilized by adding $200 \mathrm{ml}$ of detergent sodium dodecyl sulfate to $1 \%$, and the optical density (OD) of each sample was determined by an ELISA reader with a $492 \mathrm{~nm}$ filter. Cytotoxicity assays and cell viability based on the reduction of the bromide of 3-(4,5-dimethyl thiazol-2-yl)-2,5-diphenyl tetrazolium bromide (MTT) to MTT-formazan by the mitochondrial enzyme succinate-tetrazolium dehydrogenase.

For the MTT assay, L929 cells at a concentration of $2 \times 10^{5}$ cells $/ \mathrm{ml}$ were added in $30 \mu \mathrm{L}, 50 \mu \mathrm{L}$ and $100 \mu \mathrm{L}$ volumes. After $72 \mathrm{~h}$ of culture, supernatant was removed and $200 \mu \mathrm{L}$ of $1 \mathrm{mg} / \mathrm{mL}$ MTT in complete RPMI was added to the culture. Cells were incubated for $3 \mathrm{~h}$ at $37^{\circ} \mathrm{C}$ and $5 \% \mathrm{CO} 2$. After this period, the supernatant was removed and the cells were solubilized by adding $200 \mu \mathrm{L}$ of dimethyl sulfoxide (DMSO). L929 cells, at a concentration of $2 \times 10^{5}$ cells $/ \mathrm{mL}$ were seeded $(30 \mu \mathrm{l})$ in the titanium plate holes. As a control, one droplet of cells was added to samples without titanium. The plate was incubated for $2 \mathrm{~h}$ at $37{ }^{\circ} \mathrm{C}$ and $5 \% \mathrm{CO}_{2}$ for cell adherence. After this period, $500 \mu \mathrm{L}$ RPMI was added in each hole, and the plate was then incubated at $37^{\circ} \mathrm{C}$ with $5 \% \mathrm{CO}_{2}$ for $72 \mathrm{~h}$. The evaluation of the viability of cells subjected to different treatments was performed by the addition of MTT.

The ODs of the cells cultured on the A, B and C Ti cp surfaces, as well as the control cells, were compared by Kruskal-Wallis tests (Ayres et al., 2007), taking $p=0.05$ as the threshold for statistical significance.

Tests to evaluate the biocompatibility were performed following the pre-established protocols in the Instituto de Biociências, UNESP, Botucatu, from a trans-disciplinary study in accordance with
ISO 10993, 1, 5 and 6 steps (International..., 1993a, 1993b, 1990).

\section{Results}

The functionalization of the surfaces was monitored by measurements of the static contact angle using water (polar) and dimethyl sulfoxide (non-polar), such that the polar and dispersive contributions to the free energy of each surface could be verified. Figure 1 shows an example of the program used to calculate the data obtained by the tensiometer software output screen. The chart $\gamma_{\mathrm{LV}}(1+\cos \theta) /\left(\gamma_{\mathrm{LV}}^{\mathrm{d}}\right)^{1 / 2}$ versus $\left(\gamma_{\mathrm{LV}}^{\mathrm{p}} / \gamma_{\mathrm{LV}}^{\mathrm{d}}\right)^{1 / 2}$ was used to calculate the energy in terms of the dispersive and polar forces from the linear and angular coefficients, respectively. Using liquids with different properties, this method allows for the investigation of the type of surface associated with intermolecular interactions. Long-range attractive forces are influenced by fluctuating loads and are dependent on the crystallographic orientation at the interface. These forces can vary and make the component dispersive. Short-range forces are related to the polar component (e.g., the formation of hydroxyl groups on the surface; Kaelble and Uy, 1970; Owens and Wendt, 1969).

Figure 2 shows the characterization of surfaces in terms of their physical properties. With images obtained by electron microscopy is possible to evaluate the differences between the morphology and microstructure of the surfaces A, B and C before the study of the interaction with the SBF. Beside the micrographs there are the graphs of the contact angle as a function of time, starting from the first point measured by the equipment. Physically, the graphs represent the macroscopic behavior of the interaction at the interface. When evaluating the individual points, the results showed that the variation of the contact angle in the sample $B$ was more pronounced when compared with the sample $\mathrm{C}$ during the first 10 seconds. From this point, there was little variation in angle. Unlike this behavior, the $\mathrm{C}$ surfaces produced a more linear variation (next to those observed in group A). Noteworthy is also the behavior of the surface where the angle $\mathrm{C}$ continued varying significantly after 40 seconds as interfacial contact gradually increased. To determine the wettability of the SBF, it was decided to determine different time scales within a total of 10 minutes for each sample, from the determination of Modified Drops profile. The results of the angles of the right and left of the drop with the surface were analyzed, via software, to four independent experiments, in which points were chosen standard deviation $\sigma \pm 0.5$. Although the angles were measured at range of 0.05 


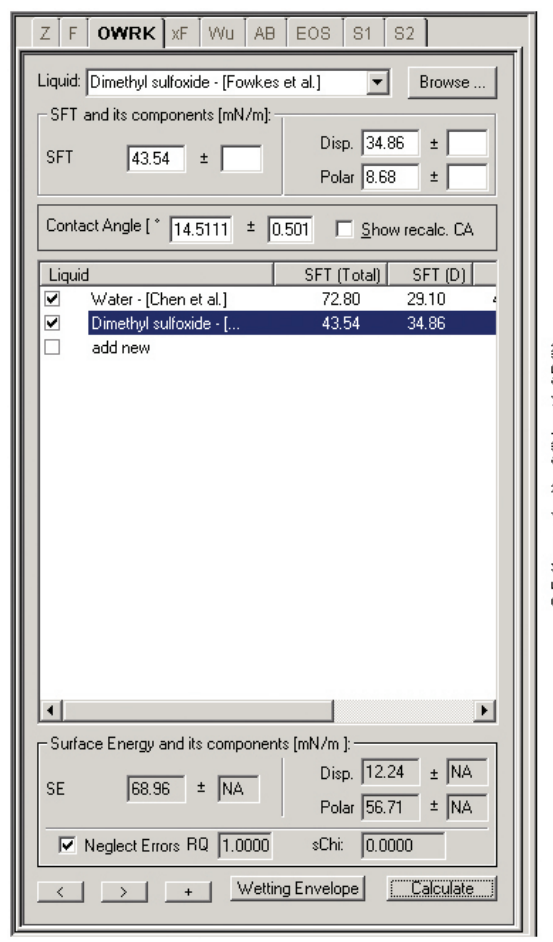

\section{SE - Plot}

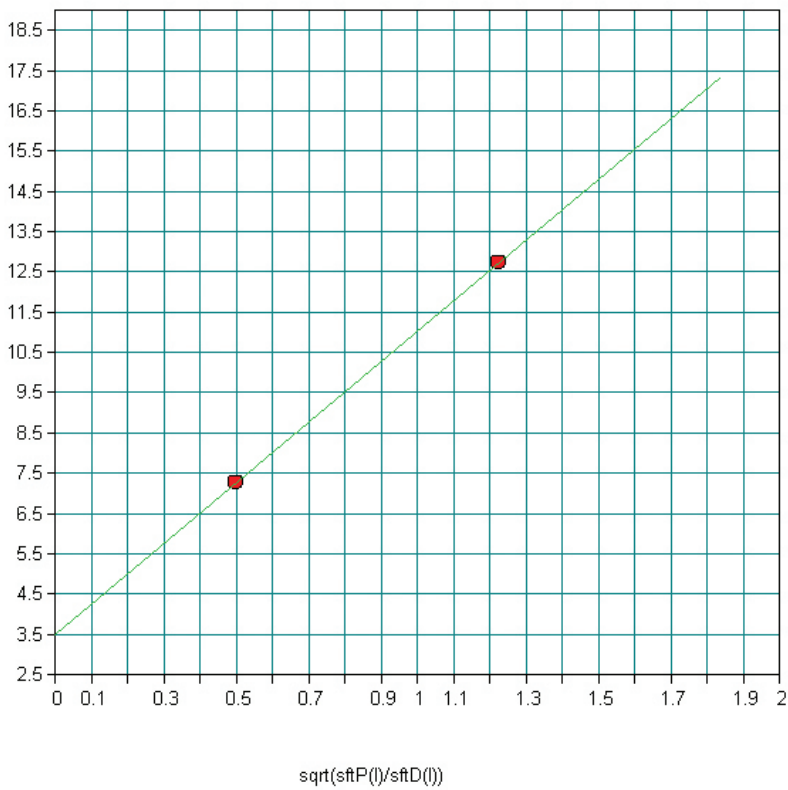

Figure 1. Example of screen output of the program used to determine the surface free energy of the titanium. Plot of $\gamma_{\mathrm{LV}}(1+\cos \theta) /\left(\gamma_{\mathrm{LV}}^{\mathrm{d}}\right)^{1 / 2}$ versus $\left(\gamma_{\mathrm{LV}}^{p} / \gamma_{\mathrm{LV}}^{\mathrm{d}}\right)^{1 / 2}$ determines (by software) the dispersive and polar components from linear and angular coefficients, respectively.

Table 1. Characteristics of the three types of titanium surfaces (groups A, B and C) in terms of physical properties: roughness obtained by atomic force microscopy, free energy and polar $\left(\gamma_{\mathrm{S}}^{p}\right)$ and dispersive $\left(\gamma_{\mathrm{S}}^{\mathrm{d}}\right)$ components obtained by static contact angle measurements (with standard deviation) and wettability of the SBF obtained by dynamic contact angle measurements. Data are mean \pm standard deviation.

\begin{tabular}{ccccccc}
\hline $\begin{array}{c}\text { Sample } \\
\text { groups }\end{array}$ & $\begin{array}{c}\text { Roughness } \\
(\mathbf{n m})\end{array}$ & $\begin{array}{c}\text { Static contact } \\
\text { angle }\left({ }^{\circ}\right)\end{array}$ & $\begin{array}{c}\text { Free energy } \\
\left(\mathbf{m J} / \mathbf{m}^{2}\right)\end{array}$ & $\boldsymbol{\gamma}_{\mathbf{s}}^{\mathbf{p}}\left(\mathbf{m J} / \mathbf{m}^{2}\right)$ & $\boldsymbol{\gamma}_{\mathbf{s}}^{\mathrm{d}}\left(\mathbf{m J} / \mathbf{m}^{2}\right)$ & $\begin{array}{c}\text { SBF wettability } \\
\left(\mathbf{x 1 0} \mathbf{0}^{-3} \mathbf{~ r a d} / \mathbf{s}\right)\end{array}$ \\
\hline $\mathbf{A}$ & 178.24 & $40.7 \pm 0.1$ & 41.01 & 0.03 & 40.98 & $6.4 \pm 0.5$ \\
$\mathbf{B}$ & 219.52 & $36.83 \pm 0.446$ & 36.67 & 13.72 & 22.95 & $8.5 \pm 0.5$ \\
$\mathbf{C}$ & 229.88 & $27.01 \pm 0.1$ & 77.41 & 69.49 & 7.91 & $12.5 \pm 0.5$ \\
\hline
\end{tabular}

to 0.1 second, the best results were obtained with $0.1 \mathrm{sec}$ measures capture.

Table 1 summarizes the physical properties obtained by the characterization of the surfaces (groups A, B and C) from Figures 1 and 2. The roughness obtained by atomic force microscopy, the polar $\left(\gamma_{\mathrm{S}}^{\mathrm{p}}\right)$ and dispersive $\left(\gamma_{\mathrm{s}}^{\mathrm{d}}\right)$ components of free energy obtained by measurements of the static contact angle and the wettability of SBF obtained by measuring the dynamic contact angle, were compared. The contact angle and wettability values are accompanied by their standard deviations. All properties were directly affected by the physico-chemical changes on the surfaces of $\mathrm{Ti}$ cp. The analyses obtained by the AFM images of Figure 2 showed roughness values equal to $178.24 \mathrm{~nm}$, $219.52 \mathrm{~nm}$ and $229.88 \mathrm{~nm}$ for groups A, B and C, respectively. Regarding the dynamics of interaction, the results show that the wettability of the SBF had an average increase of $2.0 \mathrm{rad} / \mathrm{s}$ from the A surface to the $\mathrm{B}$ surface. From the $\mathrm{B}$ surface to the $\mathrm{C}$ surface, the wettability had an average increase of $6 \mathrm{rad} / \mathrm{s}$.

To verify the functionalization of the surfaces and the physical properties affected by the biological properties, the cell viability was evaluated for the three sample groups. Table 2 shows the OD values obtained from cell cultures at different periods. Figure 3 shows the average results of the growth of L929 cells on the surfaces in four independent experiments. The results of the Kruskal-Wallis test $(p=0.0803)$ indicated no significant difference in cell growth in the analyzed samples. 

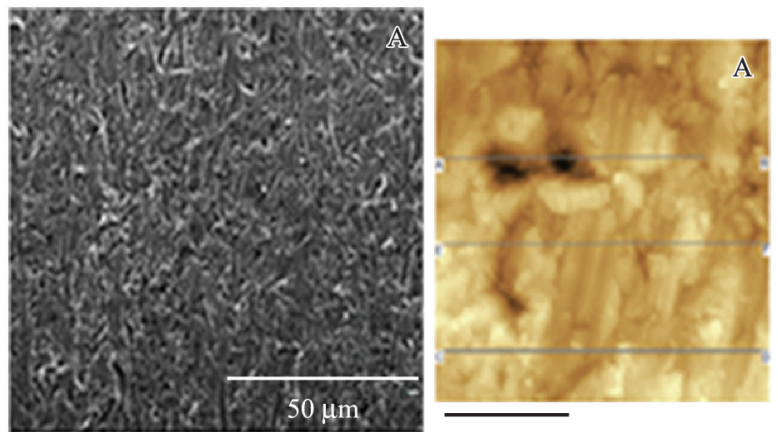

$10 \mu \mathrm{m}$
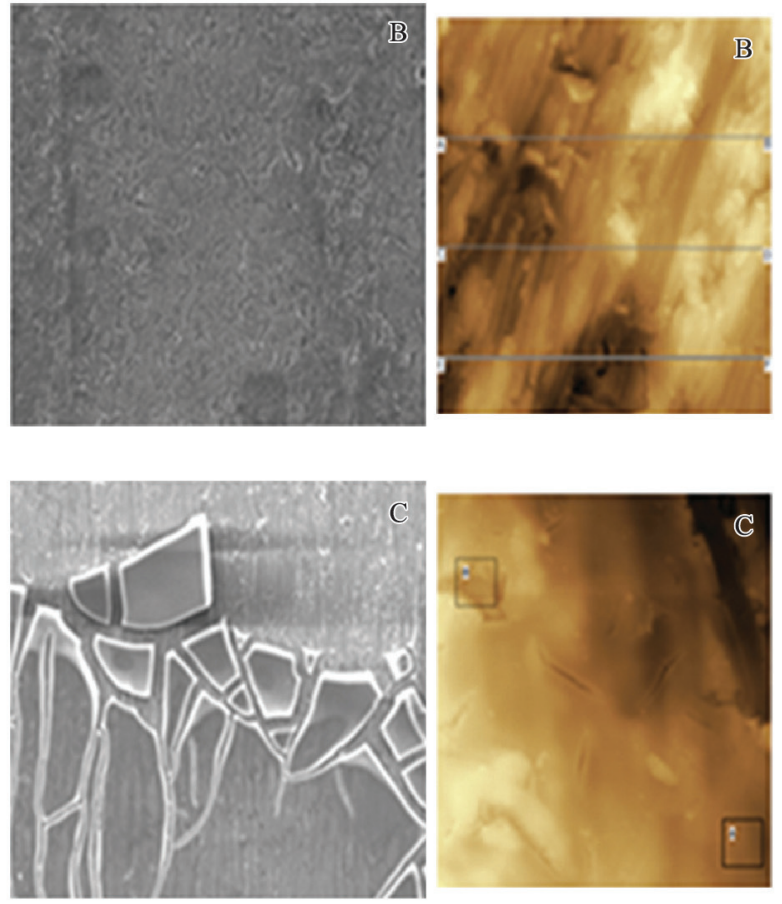
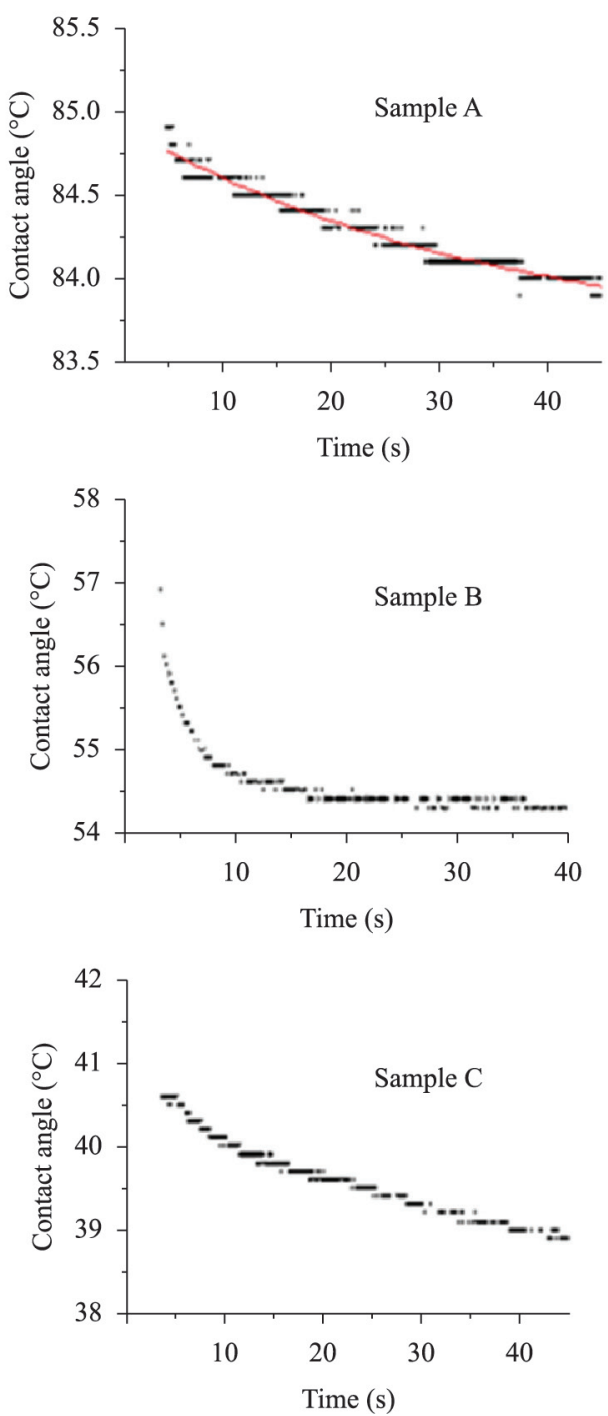

Figure 2. Characterization of the Ti cp surfaces to evaluate the different nature of the surfaces of A, B and C groups after the physicalchemical modifications. From left to right, the micrographs obtained by scanning electron microscopy to assess the morphology, the images obtained by atomic force microscopy to determine the roughness and the wettability profiles for preliminary assessment of the dynamics of interaction of the different surfaces with the simulated body fluid are shown. The scales shown in the microscopy images of group A are the same as those in the respective images of the other groups.

Table 2. Mean values of optical density accompanied by the standard deviation, corresponding to the growth of L929 cells at different times of culture.

\begin{tabular}{cccccc}
\hline $\mathbf{2 4} \mathbf{h}$ & $\mathbf{4 8} \mathbf{h}$ & $\mathbf{7 2} \mathbf{h}$ & $\mathbf{9 6} \mathbf{h}$ & $\mathbf{1 2 0} \mathbf{h}$ & $\mathbf{1 4 4} \mathbf{h}$ \\
\hline $0.080 \pm 0.01$ & $0.168 \pm 0.01$ & $0.270 \pm 0.01$ & $0.361 \pm 0.03$ & $0.558 \pm 0.02$ & $0.603 \pm 0.14$ \\
\hline
\end{tabular}

\section{Discussion}

To obtain functionalized surfaces designed to regenerate tissues and to understand their interactions with the biological environment contacting the surface, the free energy is one of the most important properties to evaluate. This property is essential to demonstrating surface activation and to investigate bone growth stages when a material is implanted in the human body. Kasemos (2002) proposed a relationship between the cell adhesion probability and high free energy. Wang et al. (2008), showed the effects of the free energy on apatite formation. Recently, Svetlana et al. (2013), related the hemocompatibility of the modified 


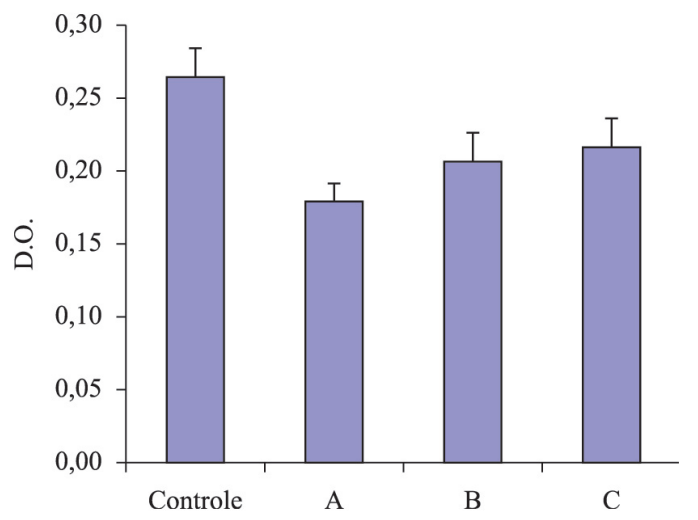

Figure 3. Means and standard deviation of optical density of L929 cultures grown on surfaces A, B and C of Ti cp, and of control cells cultured in the absence of titanium.

surfaces with the characteristics of the free energy components. In this work, these properties were evaluated, accounting for the polar and dispersive components, by measuring the static contact angle and applying the theories as described earlier. Figure 1 shows an example of the screen output containing all parameters used for analyses. The free energy results of Table 1 show the different characteristics of the three surfaces. It is possible to explain the quality of the formed titanium coating, especially in the group $\mathrm{B}$ (alkaline treatment) and group $\mathrm{C}$ (calcium $+\mathrm{TiO}_{2}$ treatment) samples. The decrease of the dispersive forces observed in these groups implies a corresponding decrease of the long-range forces, leading to a decrease in the forces that promote the adhesion and stability of the coat. The $\mathrm{C}$ surface was characterized with low mechanical stability. This is due to structural changes in the oxide layers. Their microstructure and morphology can be observed in the images of Figure 2. However, the acid treatment of the samples of group A altered the passivation layer (oxide formed). The $\mathrm{H}^{+}$Ti metal that remains on the surface results in interactions with permanent dipole moments and low energies per polarization (approximately $0.03 \mathrm{~mJ} / \mathrm{m}^{2}$ ). The charge fluctuations resulting from intermolecular forces over long distances are more intense (approximately $49 \mathrm{~mJ} / \mathrm{m}^{2}$ ), which affects the value of the dispersive energy component of group A, as shown in Table 1. This increase is expected and is necessary for the system to be thermodynamically stable.

Different intermolecular interactions between the surface of the material and the biological environment can be obtained from chemical-physical modifications on the surfaces of the samples. These interactions are the result of long-range attractive forces (dispersive component) and short-range forces (polar component). Understanding these interactions may provide answers about the interfacial phenomena. The short-range forces can be explained by the superposition of the electron clouds promoted by the formation of $(\mathrm{OH})^{-}$ groups on the titanium surfaces. The formation of these functional groups can be confirmed by the data of Table 1, which shows an increase in the polar component of group B (alkali treatment) and group $\mathrm{C}$ (calcium coating treatment). In the first case, the $\mathrm{NaOH}$ treatment based promoted the formation of an oxide layer (Figure 2 group B), indicating a sodium ion diffusion into the oxides structures, as a consequence, forming sodium titanate phases $\left(\mathrm{Na}_{2} \mathrm{TiO}_{3}\right)$. This type of interfacial phenomenon was observed by Wang et al. (2008), in which $\mathrm{NaOH}$ alkaline treatments on titanium surfaces showed that the sodium titanate phase induced the formation of apatites when immersed in SBF. Following this observation, the $\mathrm{CaTiO}_{3}$ phases may have formed on the surfaces of group $\mathrm{C}$ samples. Thermal treatment at $700{ }^{\circ} \mathrm{C}$ allowed for $\mathrm{Ca}^{2+}$ diffusion into the oxide structures, promoting a higher density of $(\mathrm{OH})^{-}$particles in the superficial layers. This hypothesis is supported by a significant increase in the surface polarization of the group $\mathrm{C}$ samples, as estimated by calculating the component (Table 1). The calcium-based coating formed on the surface can act as a reservoir, releasing $\mathrm{Ca}^{2+}$ ions present in the superficial layers and influencing the stages of the osseointegration process.

It is vital that the energy component data also take into account the variation of the microstructure (SEM micrographs of Figure 2). The free energy is also dependent on the increased surface area, and the effect of this property can be seen in the roughness profiles. This property has a direct influence on the proliferation of bone cells and has been studied in terms of width, depth and number of grooves, with results showing that it is a critical factor in determining a positive reaction and cell orientation on the substrate (Nadim et al., 2001). However, because the early stages of interaction with biological fluids is not well characterized for this property, especially the wettability of the body fluid, it is necessary to relate these two properties. From the results of surface roughness measurements, two observations can be highlighted. The first is related to the slight decrease of the free energy of surface B in comparison with surface A, despite an increased roughness. However, both $A$ and B presented activated surfaces. Wang et al. (2008), estimated a value of $33.3 \mathrm{~mJ} / \mathrm{m}^{2} \mathrm{Ti} \mathrm{cp}$. Despite the difference in roughness between samples $B$ and $C$ is less than that between samples A and B, the second observation is that the difference in the free energy between the first two samples was greater, which indicates that the effects of the chemical nature are more significant than the dimensions of the surface 
area. By analyzing the energy components, the surface activation of group $\mathrm{C}$ samples is provided by surface polarization forming $(\mathrm{OH})^{-}$groups. However, the oxidecoated surfaces showed lower mechanical stability because of decreasing long distance forces, as seen in the decrease in the dispersive energy (Table 1).

To investigate how roughness and free energy govern tissue regeneration properties, research on the wettability of the SBF on the three surfaces has been conducted such that it was not possible to consider the thermodynamic equilibrium (Lyklema, 2000; Marmur, 2000; Motta et al., 2004; Park et al., 2012). In Figure 2, it is possible to see the differences of the wettability curves of the SBF soon after contact. Starting from the first point measured by the equipment, it is possible to observe the difference of the initial contact angle, thereby characterizing the difference in hydrophilicity. These first steps were essential for the following tests; it became apparent that the effects varied in each type of surface indicating that the polarization forces of the surfaces influenced the dynamic spreading as the interfacial contact gradually increased. It is important to emphasize that SBF was used to obtain as physiologically representative conditions of the early stages of the interactions between the human body and material. The free energy hypothesis can be described by the interactions between $\mathrm{Ca}^{2+}, \mathrm{Mg}^{2+}$ and $\mathrm{Na}^{+}$, which make up the body fluid, with the $(\mathrm{OH})^{-}$groups available on the surface (which are especially seen in group $\mathrm{C}$ samples) that contribute to the SBF spreading speed. Similarly, the nature of the surface of an implant can influence the early stages of the tissue regeneration process, because a greater wettability of the body fluid indicates a higher affinity for the biological environment.

The interfacial interactions discussed here are related to short-range forces. However, it is recognized that these interactions may lead to macroscopic effects, which raises additional concerns. Can these forces produce more marked effects on the wettability of SBF than the effects of surface roughness? Is there a proportional contribution of these force interactions with macromolecules, such as osteoblast precursor cells? With regards to the first concern, by studying the parameters in Table 1, it appears that the effects of wettability are more pronounced than the roughness due to the polarization of sample $\mathrm{C}$ surfaces. Thus, one of the aims of this study is to establish a relationship between the wettability and the dispersive and polar components of the surface energy to assess the contribution of intermolecular forces. To address the second concern, the dynamics of interface interactions through the wettability between cells and surfaces, requires in vitro experiments as described earlier. Figure 3 shows the averages of the results of the growth of L929 cells in four independent cultures on surfaces
A, B, C and control cells. Despite a Kruskal-Wallis test $p$ value of 0.08 , the differences were near the limit of statistical significance $(p=0.05)$ to suggest the possibility of significance if the sampling set is increased. Thus, further tests need to be performed to establish a potential correlation between the physical and biological properties. Within this context it is important to emphasize that group $\mathrm{C}$ surfaces showed high dispersive components and low polarities. Both total free energy and the wettability of the SBF for these surfaces were lower when compared with that of the other groups.

Finally, it is important to highlight that the wettability of the SBF, observed in the experiments described in this article, was directly influenced by the forces arising from polarization, which were more pronounced than contributions due to surface roughness. This phenomenon can be attributed to the nature of the hydroxyl groups that provided interactions between surfaces and ions present in the body fluid. These polar forces are the most significant contributions that activate the surface and increase their wettability. Because these interactions influence the SBF spreading dynamics, it is possible that this may also affect cell viability. Further experiments will be required to improve the presented methodology to be used as a tool for the preliminary assessment of biomaterials without the use of in vivo experiments.

\section{Acknowledgements}

The authors express their gratitude to Dr. Douglas Monteiro, Dr. Elisabete Zaniquelli and Dr. Ivana Aparecida Borin (USP, Ribeirão Preto); Dr. Ramon Kaneno, Dr. Tereza Peraçoli and Dr. Margarida Saeki (UNESP, Botucatu); Dr. José Silvio Govone from (UNESP, Rio Claro), Instituto de Ortopedia e Traumatologia IOT, Indústria Bionnovation Biomedical, CNPq, CAPES and FAPESP.

\section{References}

Abdel-Fattah WI, Reicha FM, Elkhooly TA. Nano-beta tricalcium-phosphate sinthesis and biodegradation. Biomedical Materials. 2008; 3:1-13. PMid:18765896. http://dx.doi.org/10.1088/1748-6041/3/3/034121

Ayres M, Ayres M Jr, Ayres DL, Santos AS. BioEstat 5.0. Brasília: Ministério da Ciência e Tecnologia; 2007. p. 59-74.

Boyan BD, Hummert TW, Dean DD, Schwartzet Z. Role of material surfaces in regulating bone and cartilage cell response. Biomaterials. 1996; 1:137-46. http://dx.doi. org/10.1016/0142-9612(96)85758-9

Branemark P-I, Zarb GA, Albrektsson T. Protesis tejido-integradas. La oseointegración en la odontología clínica. Quintessenz Verlangs-GmbHBerlin. Ed. Especial Nobelpharma. 1987; 1:226-7. 
Bruce DB, Peter GT, Levine AM, Neil EG, Swiontkowski MF. Skeletal trauma: basic science, management and reconstruction. New York: Saunders; 2003. v. 1, n. 3, p. 195-249.

Galdino AGS, Zavaglia CAC. Physical-mechanical characterization of hydroxyapatite-titanium oxide composite prepared by the polymeric sponge method. Cerâmica. 2012; 58:388-91. http://dx.doi.org/10.1590/ S0366-69132012000300017

Giavaresi G, Fini M, Cigada A, Chiesa R, Rondelli G, Rimondini L, Torricelli P, Aldini NN, Giardino R. Mechanical and histomorphometric evaluations of titanium implants with different surface treatments inserted in sheep cortical bone. Biomaterials. 2003; 24:1583-94. http://dx.doi.org/10.1016/ S0142-9612(02)00548-3

International Organization for Standardization. ISO 10993-5: Biological evaluation of medical devices. Part.5: Tests for Citotoxicity: in vitro methods. ISO; 1993a.

International Organization for Standardization. ISO 10993: Biological evaluation of medical devices. Part 1: Guidance on selection of tests. Part 6: Tests for local effects after implantation. ISO; 1993 b.

International Organization For Standardization. ISO 10993-TC194-WG1: Systematic approach to biological evaluation international standard. ISO; 1990.

Israelachvili J. Intermolecular and surface forces. 2nd ed. San Diego: Academic Press Inc.; 1992.

Kaelble DH, Uy KC. A reinterpretation of organic liquid-polytetrafluoroethylene surface interactions. Journal of Adhesion. 1970; 2:50. http://dx.doi. org/10.1080/0021846708544579

Kasemos B. Biological surface science. Surface science. 2002; 500:656-77. http://dx.doi.org/10.1016/ S0039-6028(01)01809-X

Kizuki T, Takadama H, Matsushita T, Nakamura T, Kokubo T. Preparation of bioactive Ti metal surface enriched with calcium ions by chemical treatment. Acta Biomater. 2010; 6:2836. PMid:20074675. http://dx.doi. org/10.1016/j.actbio.2010.01.007

Kokubo T. Bioactive glass ceramics: properties and applications. Biomaterials. 1991; 12:155-63. http://dx.doi. org/10.1016/0142-9612(91)90194-F

Lyklema J. Fundamentals of interface and colloid science: liquid-fluid interfaces. San Diego: Academic Press Inc.; 2000. PMid:10942556.
Marmur A. Wetting on real surfaces. Journal of Imaging Science and Technology. 2000; 44:406-9.

Motta FV, Balestra RM, Ribeiro S, Taguchi SP. Wetting behaviour of SiC ceramics. Part I E2O3/A12O3 additive system, Material. Letter. 2004; 58:2805-9. http://dx.doi. org/10.1016/j.matlet.2004.05.005

Nadim JH, Kirk JB, Kim OC, Randy LM, Joshua JJ. Evaluation of metallic and polymeric biomaterial surface energy and surface roughness characteristics for directed cell adhesion. Tissue Engineering. 2001; 7(1):55-71. PMid:11224924. http://dx.doi.org/10.1089/107632700300003297

Nascimento RM. Fenômenos Interfaciais resultantes de modificações físico-químicas em superfícies metálicas para aplicações biomédicas [thesis]. Universidade Estadual Paulista; 2011.

Owens DK, Wendt RC. Estimation of the surface free energy of polymers. Journal of Applied of Polimer Science. 1969; 13:1741. http://dx.doi.org/10.1002/ app.1969.070130815

Park JH, Wasilewski CE, Almodovar N, Olivares-Navarrete R, Boyan BD, Tannenbaum R, Schwartz Z. The response to surface wettability gradients induced by chitosan nanofilms on microtextured titanium mediated by specific integrin receptors. Biomaterials. 2012; 33:7386-93. PMid:22835642 PMCid:PMC3781581. http://dx.doi.org/10.1016/j. biomaterials.2012.06.066

Stevens MM. Biomaterials and tissue engineering. Materials Today. 2008; 11:18-25. http://dx.doi.org/10.1016/S13697021(08)70086-5

Svetlana AS, Daniel S, Erik H, Markus R. Evaluation of wettability and surface energy of native Nitinol surfaces in relation to hemocompatibility. Materials Science and Engineering C. 2013; 33:127-32. http://dx.doi.org/10.1016/j. msec. 2012.08 .018

Thein Han W, Liu J, Xu HH. Calcium phosphate cement with biofunctional agents and stem cell seeding for dental and craniofacial bone repair. Dental Materials. 2012; 28:105970. PMid:22809583 PMCid:PMC3535491. http://dx.doi. org/10.1016/j.dental.2012.06.009

Wang XJ, Li YC, Lin JG, Hodgson PD, Wena CE. Apatiteinducing ability of titanium oxide layer on titanium surface: The effect of surface energy. Journal of Materials Research. 2008; 23:1682-8. http://dx.doi.org/10.1557/ JMR.2008.0195

\section{Authors \\ Rodney Marcelo do Nascimento* \\ Departamento de Física, Universidade Estadual Paulista - UNESP, Av. 24 - A, 1515, Bela Vista, CEP 13506-900, Rio Claro, SP, Brasil. Instituto de Física, Universidade de São Paulo - USP, Av. Trabalhador são-carlense, 400 - Pq. Arnold Schimidt, CEP 13566-590, São Carlos - SP - Brasil.}

